\title{
Apoio Comportamental Positivo: Estratégias Educacionais Aplicadas a Comportamentos-Problema de Alunos
}

\author{
Karyne de Souza Augusto Rios ${ }^{1}$ \\ Centro Universitário Adventista de São Paulo \\ Fátima Elisabeth Denari \\ Universidade Federal de São Carlos
}

\begin{abstract}
RESUMO - Baseado no modelo de Apoio Comportamental Positivo o estudo objetivou identificar como 40 diretores de escolas de educação infantil descreviam o processo de elaboração, aplicação e avaliação de estratégias educativas para comportamentosproblema de alunos. Resultados do questionário apontaram que 77,5\% dos diretores indicaram comportamentos-problema em seus alunos. As estratégias educativas mais utilizadas foram conversar com a criança (13,3\%) e conversar com pais (13,3\%). A ação mais utilizada para a avaliação foi a observação da criança $(27,6 \%)$. De forma geral, verificou-se que as estratégias utilizadas foram realizadas informal e assistematicamente. Aponta-se a necessidade de pesquisas sobre a inclusão de crianças com comportamentos-problema e o desafio de repensar a formação dos educadores.
\end{abstract}

Palavras-chave: inclusão; educação infantil; comportamentos-problema; Apoio Comportamental Positivo.

\section{Positive Behavior Support: Educational Strategies for Problematic Behavior of Pupils}

\begin{abstract}
This study, based on the model of Positive Behavior Support, aims to identify how 40 primary school directors describe the process of development, application, and evaluation of educational strategies for pupils with behavioral problems. The results from a questionnaire indicated that $77.5 \%$ of the directors had pupils with behavioral problems. The most commonly used educational strategies of intervention were to speak with the child (13.3\%) or with the parents (13.3\%). The most common action for evaluation was observation of the child (27.6\%). In general, the study verified that the strategies were employed informally and unsystematically. These findings indicate that research about the inclusion of children with behavioral problems is needed and challenge to rethink about the educators professional training.
\end{abstract}

Keywords: inclusion; elementary education school; behavioral problems; Positive Behavior Support.

Segundo dados do Censo Escolar (MEC/INEP, 2005), o atendimento inclusivo no Brasil cresceu de $24,7 \%$ em 2002, para $41 \%$ em 2005. Especificamente em 2005 foram realizadas 640.317 matrículas de alunos com necessidades especiais, sendo que 12,4 \% (79.850) dessas matrículas são referentes aos alunos que apresentam condutas típicas (fobias, timidez, ansiedade, agressividade), grupo no qual se encontram a maior parte de crianças que apresentam comportamentos-problema. É o segundo maior grupo de matrículas, perdendo apenas para o número de matrículas para alunos com deficiência mental (MEC/INEP, 2005). Apesar de não existirem dados oficiais, pelo MEC, sobre a permanência desses alunos na escola, a literatura aponta que o índice de conclusão do curso escolar por alunos com comportamentos-problema é muito baixo em função das dificuldades de relacionamento social e de aprendizagem que esses alunos enfrentam (Bandeira, Rocha, Souza, Del Prette \& Del Prette, 2006; Ferreira \& Marturano, 2002; Marinho, 2003; Hallahan \& Kauffamn, 2003; Worthington \& Gargiulo, 2003).

Adicionalmente ao fato de que a taxa de permanência escolar é baixa, a literatura ainda aponta que a prevalência

1 Endereço para correspondência: Karyne de Souza Augusto Rios. Rua Passeio das Palmeiras, no. 501, apto. 73, Ed. Giardino di Ravello, Parque Faber, São Carlos, SP, CEP: 13561-260. Telefone: (16) 3411-2772. E-mail: karynerios@yahoo.com.br de crianças com comportamentos-problema atinge índices alarmantes, chegando a $35 \%$ em famílias de baixa renda (Reid, Webster-Stratton \& Beachaine, 2001), configurando uma das queixas mais freqüentes dos professores e pais (Baraldi \& Silvares, 2003; Hallahan \& Kauffmam, 2003; Marturano, 2004; Patterson, Reid \& Dishion, 1992; Webster-Stratton, Reid \& Hammond, 2004; Worthington \& Gargiulo, 2003). Tal fato pode e deve ser considerado um caso de saúde pública, em função de sua prevalência epidêmica e das suas conseqüências devastadoras, visto que, crianças com comportamentos-problema e que não recebem ajuda em tempo, podem manter esses padrões de comportamento, iniciando uma trajetória de problemas acadêmicos, evasão escolar, abuso de substâncias, transtornos de conduta, causando reflexos até mesmo na fase adulta com o surgimento de condutas criminosas e institucionalização (Gomide, 2003; Patterson \& cols., 1992; Webster-Straton \& cols., 2004).

Observa-se uma grande confusão ao se falar sobre comportamentos-problema em crianças, a começar pela variedade de definições e termos utilizados para esses comportamentos. O presente artigo adota a definição de comportamentos-problema como déficits e/ou excessos comportamentais que dificultariam 'saltos comportamentais' (Rosales-Ruiz \& Baer, 1997) isto é, repertórios que prejudicariam o acesso da criança a novas contingências de reforçamento, que por sua vez, 
facilitariam a aquisição de repertórios relevantes de aprendizagem (Bolsoni-Silva, Marturano, Pereira \& Manfrinato, 2006). A partir dessa definição, os comportamentos-problema não são vistos como categorias ou sintomas, como observadas em outras definições de caráter médico-psicológico, mas sim, como relações entre os repertórios comportamentais de um indivíduo (aprendidos pela sua história de reforçamento) e as conseqüências produzidas no ambiente por esses repertórios que, no caso dos comportamentos-problema, referem-se às conseqüências que geram efeitos adversos para a aprendizagem do indivíduo e, portanto, para a sua vida. Essa definição desfavorece a busca de diagnósticos e conseqüentemente a origem de rótulos ou estereótipos favorecendo, assim, uma visão relacional e funcional dos problemas de comportamento.

Segundo a teoria sócio-interacionista de desenvolvimento de problemas de comportamento (Patterson \& cols., 1992), pais, cuidadores e professores teriam importante papel no surgimento e manutenção dos comportamentos-problema da criança por meio de suas estratégias educativas. Weber, Viezzer e Brandenburg (2004) pontuam que o termo "estratégias educativas" está relacionado ao ato de disciplinar e que esse, por sua vez, possui dois grandes campos de definição: (1) controlar, punir e corrigir e, (2) ensinar, guiar e influenciar. A segunda definição é considerada mais atual e eficaz, porém, menos utilizada (Patterson \& cols., 1992; Weber \& cols., 2004) enquanto que a primeira definição é o sentido mais utilizado e ironicamente o menos eficaz (Safran \& Oswald, 2003) caracterizado pelo uso da punição como forma de disciplina e correção de comportamentos-problema da criança.

Skinner (1953/1998) aponta a punição como a técnica de controle mais comum da vida moderna. A técnica consiste na apresentação de um estímulo aversivo (punição positiva) ou na retirada de reforçadores positivos (punição negativa) com a intenção de reduzir a tendência de se comportar de determinada maneira. Segundo as palavras do próprio Skinner (1953/1998) “o padrão é familiar: se alguém não se comporta como você quer, castigue-o; se uma criança tem mau comportamento, espanque-a; se o povo de um país não se comporta bem, bombardeio-o" (p.199). Os alunos que apresentam comportamentos-problema normalmente acabam sendo submetidos a condições educacionais aversivas constantes (Hallahan \& Kauffmam, 2003; Patterson \& cols., 1992; Worthington \& Gargiulo, 2003) e, como exemplos de situações punitivas às quais os alunos que apresentam problemas de comportamento estão expostos em sala de aula pode-se citar broncas, ameaças e castigos. Adicionalmente, não é somente na sala de aula que o aluno recebe punições. A escola como um todo é responsável por patentear o método punitivo quando utiliza-se de suspensões e expulsões, colaborando ainda mais para a exclusão dos alunos que apresentam algum tipo de problema de comportamento.

Skinner (1953/1998) destaca que, apesar de a punição, como técnica, ter um efeito imediato na redução de uma tendência para agir de certa maneira, observa-se, também, que a longo prazo, tal técnica não elimina o comportamento problemático de um repertório. Além disso, seus efeitos de redução imediata são obtidos com alto custo para o organismo punido (criança) e para a agência punidora (escola, pais, sociedade). Esse alto custo é resultado de alguns subprodutos produzidos pela punição: depressão, raiva, ansiedade, redu- ção da autoestima e contracontrole (expressas em atitudes de rebeldia e de enfrentamento). O uso freqüente de punições gera combinações perigosas entre esses subprodutos que interferem significativamente na aprendizagem e socialização das crianças (Jacob, 2001; Marturano, 2004; Marturano, Linhares, Loureiro \& Machado, 1997) e favorecem, ainda mais, o desenvolvimento de comportamentos-problema (Bandeira \& cols., 2006; Ferreira \& Marturano, 2002; Ormeño \& Williams, 2006; Picado \& De Rose, 2009). Dessa forma, restam os seguintes caminhos para uma criança com comportamentos-problema: fracasso escolar, rejeição social, tornar-se vítima de preconceitos, baixa autoestima, depressão, ansiedade, agressividade, participação de grupos desviantes, saída da escola, abuso de substâncias e condutas criminosas (Gallo \& Williams, 2006; Gomide, 2003; Patterson \& cols., 1992; Webster-Straton \& cols., 2004;).

Em reação a todas as práticas educativas punitivas apresenta-se um enfoque mais colaborativo e preventivo nomeado de Apoio Comportamental Positivo, expressão traduzida de Positive Behavior Support- PBS (Heineman, Dunlap \& Kincaid, 2005; Safran \& Oswald, 2003). O modelo PBS é um enfoque baseado em avaliações que apresentam uma variedade de estratégias que tem como finalidade prevenir comportamentos-problema e promover comportamento pró-social (Carr \& cols., 1999; Carr \& cols., 2002; Heineman \& cols., 2005; Safran \& Oswald, 2003; Sugai \& cols., 2000). O PBS surgiu em meados da década de 1980, nos Estados Unidos, baseado nos princípios da análise aplicada do comportamento (Heineman \& cols., 2005) incorporando também, valores e estratégias advindas da teoria sistêmica (Carr \& cols., 2002; Heineman \& cols., 2005; Safran \& Oswald, 2003). Segundo Heineman e cols. (2005), o enfoque PBS é um processo caracterizado em quatro etapas: (1) identificação e engajamento dos participantes; (2) identificação das variáveis associadas ao comportamento; (3) seleção e implementação das estratégias com enfoque no PBS e, (4) monitoramento e avaliação dos resultados. A identificação e o engajamento dos participantes envolvem a formação de um grupo de apoio composto por pessoas que estejam envolvidas com a criança (por exemplo, alunos, professores, pais, coordenadores, psicólogo escolar, etc.).

O grupo de apoio é formado com o intuito de resolver problemas e prover apoio para os alunos com problemas de comportamento por meio de uma comunicação aberta, honesta e respeitosa, buscando os mesmos objetivos, dividindo responsabilidades e resolvendo conflitos por meio de consenso (Heineman \& cols., 2005). Após a formação do grupo de apoio, é necessário identificar exatamente quais variáveis, condições ou eventos estão contribuindo para o comportamento do aluno. Essa compreensão das variáveis é frequentemente obtida por meio da Análise Funcional do Comportamento, termo traduzido da expressão Functional Behavior Analysis- FBA (Conroy \& Stichter, 2003; Ervin \& cols., 2001; Reid \& Nelson, 2002; Scott \& Eber, 2003) que pode ser definida como um processo de solução de problemas que tem como objetivos definir claramente os comportamentos considerados inadequados; identificar eventos, ocasiões e situações que prevêem quando um comportamento irá ou não ocorrer; determinar as conseqüências que mantêm o comportamento-problema; e, gerar 
hipóteses que possam definir as relações entre variáveis (Heineman \& cols., 2005).

A terceira etapa do PBS, que envolve a seleção e a implementação de estratégias, é realizada com base nos dados da FBA. A intervenção deve utilizar multicomponentes e incluir estratégias que visem prevenir problemas pela modificação das condições do ambiente, ensinar repertórios novos para substituir os comportamentos considerados inadequados e prover conseqüências positivas para os comportamentos adequados. Por fim, a última etapa do PBS, que envolve o monitoramento e avaliação dos resultados, ocorre por meio da coleta de dados realizada tanto na fase de construção da intervenção quanto na fase de avaliação da mesma. O objetivo da avaliação é verificar mudanças nos comportamentos considerados alvos da intervenção e identificar alterações consideradas positivas em outros contextos nos quais a criança se relaciona. As formas como os dados são coletados podem variar conforme as circunstâncias, mas em geral incluem medidas de freqüência dos comportamentos-alvo, uso de escalas ou checklists, observações, medidas de satisfação e medidas advindas de outros ambientes relacionados à criança (Heineman \& cols., 2005).

Adicionalmente, o PBS pode ser aplicado em três níveis de atuação na escola (primário, secundário, terciário) para efetivamente apoiar e incluir todos os alunos. Os níveis representam uma hierarquia de prevenção que objetiva tornar a ocorrência dos comportamentos-problema menos prováveis (Heineman \& cols., 2005). Segundo Scott e Eber (2003), o nível de intervenção primária seria implementado em toda a escola e para todos os alunos. Pesquisas apontam que, quando bem realizada, a intervenção de caráter primário é capaz de ser efetiva em 80 a $90 \%$ de todos os alunos da escola. Desta forma, os alunos que continuam a demonstrar problemas são encaminhados para os níveis de intervenção secundária e terciária que aplicam estratégias mais intensivas e individualizadas (Scott \& Eber, 2003). Segundo os mesmos autores, a intervenção secundária envolveria a atuação do grupo de apoio que seria responsável por elaborar e aplicar estratégias direcionadas para alunos que foram encaminhados por outras instituições ou para grupos pequenos de alunos. A intervenção terciária seria endereçada para alunos com necessidades crônicas ou mais complexas que não puderam ser atendidas pelos níveis primário e secundário. O processo nesse nível requer avaliações detalhadas das necessidades da criança por meio da colaboração de todas as pessoas envolvidas com a criança. A partir dessa criteriosa avaliação inicial o grupo de apoio formula o plano de ação que variará de acordo com a quantidade e complexidade de necessidades da criança e a variedade dos ambientes envolvidos com a criança (Scott \& Eber, 2003).

Apesar das pesquisas sobre o PBS e comportamentos-problema serem realizadas há mais de 10 anos nos Estados Unidos, observa-se que no Brasil ainda existe uma carência de pesquisas sobre o assunto. Nota-se, no Brasil, a prevalência de pesquisas de caráter relacional com o objetivo de identificar relações entre a presença de comportamentos-problema e outras variáveis, tais como: desempenho acadêmico (Ferreira \& Marturano, 2002; Marturano, 2004; Medeiros, Loureiro, Linhares \& Marturano, 2000), práticas educativas (Bolsoni-Silva \& Marturano, 2002; Salvo, Silvares \& Toni,
2005), ambiente familiar (Ferreira \& Marturano, 2002), habilidades sociais e problemas de aprendizagem (Bandeira $\&$ cols., 2006). Os estudos que procuram avaliar intervenções mostram-se ainda preliminares e com dados bastante incipientes. Em geral, as intervenções são realizadas com os pais (Baraldi \& Silvares, 2003; Pinheiro, Haase, Del Prette, Amarante \& Del Prette, 2006; Rios \& Williams, 2008; Santos \& Williams, 2006; Serra-Pinheiro, Guimarães \& Serrano, 2005) e poucas intervenções são realizadas no contexto escolar (Ormeño \& Williams, 2006; Picado \& De Rose, 2009).

Dentro do contexto de educação infantil o papel do diretor escolar apresenta-se como fundamental na elaboração e condução de estratégias educativas em função de sua situação privilegiada de gestor responsável por liderar, gerenciar e articular o trabalho de professores. Nesse sentido, o diretor não é apenas o representante administrativo e legal da escola mas, também, o condutor dos projetos pedagógicos, sendo a pessoa responsável por responder pelos resultados de aprendizagem dos alunos de sua escola.

Em um estudo sobre a revisão de produção científica sobre a qualidade da educação infantil brasileira, Campos, Füllgraf e Wiggers (2006) apontaram que em geral os diretores ou gestores de escola de educação infantil são normalmente professores que são indicados para o cargo com o desafio de implementar as mudanças propostas em lei na multifacetada realidade educacional brasileira. Segundo os autores supracitados o diretor acaba exercendo dentro das escolas uma variedade de funções que vão desde o apoio psicopedagógio às funções de gerenciamento administrativo de recursos. Nesse sentido, observa-se que essa variedade de funções lhe garante um olhar amplo sobre todo o funcionamento escolar e suas demandas. Por isso, nesse estudo foram selecionados como participantes os diretores, em função de sua atuação geral nas demandas escolares.

Portanto, tendo como modelo as premissas teóricas do enfoque PBS e visando aumentar o conhecimento na área sobre comportamentos-problema de crianças em contexto escolar, esse estudo procurou identificar como os diretores de escolas municipais de educação infantil descreviam o processo de elaboração, aplicação e avaliação de estratégias educativas para os alunos com comportamentos-problema.

\section{Método}

\section{Participantes}

Participaram da pesquisa 40 diretores das escolas municipais de educação infantil (EMEIs) que atendem crianças entre três a cinco anos de idade residentes em uma cidade de 200.000 mil habitantes do interior do estado de São Paulo.

\section{Instrumento}

Foi elaborado pelas pesquisadoras um questionário preliminar com base no modelo do PBS e FBA (Conroy \& Stichter, 2003; Hieneman \& cols., 2005; Reid \& Nelson, 2002; Safran \& Oswald, 2003; Scott \& Eber, 2003). O ques- 
tionário foi enviado a três juízes que eram pesquisadores na área de comportamentos-problema e inclusão. Aos juízes foi solicitado que lessem cada questão do questionário e verificassem se a questão era pertinente com os objetivos da pesquisa e apontassem sugestões ou alterações para melhoria do instrumento. Após avaliação dos juízes, foram realizadas as reformulações consideradas pertinentes e aplicado o questionário em duas pessoas com características semelhantes dos participantes do estudo. Essa aplicação piloto visou avaliar se os itens eram de fácil compreensão e se os respondentes compreendiam o que estava sendo solicitado.

A versão final do questionário consistia de 25 perguntas, sendo que as primeiras 15 perguntas visavam coletar informações sobre a escola (localização), direção (tempo em que o respondente estava no cargo de diretor), profissionais (quantidade de profissionais, formação técnica do staff), professores (quantidade de professores e formação técnica dos mesmos) e alunos (quantidade de alunos e quantidade de alunos com comportamentos-problema).

As demais 10 perguntas possuíam perguntas fechadas [por exemplo: "Você costuma conversar (formal ou informalmente) com outras pessoas para discutir questões sobre como ajudar os alunos com problemas de comportamento?'] e abertas ("Segundo sua opinião, liste na tabela abaixo, as características demonstradas por alunos que apresentam problemas de comportamento"). Essas perguntas tiveram por objetivo: (1) identificar quais as pessoas envolvidas na formulação das estratégias para ajudar crianças com problemas de comportamento; (2) verificar como são identificados os contextos em que ocorrem os problemas de comportamento; (3) identificar quais são as estratégias utilizadas pela escola para ajudar os alunos com problemas de comportamento; (4) e identificar se as estratégias implementadas pela escola para ajudar os alunos com problemas de comportamento são avaliadas e de que forma é realizada a avaliação. Em função do objetivo do presente estudo foram apresentadas as análises referentes a esse grupo de perguntas que abordavam as questões ligadas às estratégias educativas.

\section{Procedimento}

O projeto de pesquisa juntamente com o questionário em sua versão preliminar, foram encaminhados à Secretaria de Educação da cidade para autorização de realização do mesmo. Após autorização da Secretaria de Educação, o projeto de pesquisa foi encaminhado para o Comitê de Ética da universidade à qual os autores são filiados. Com a aprovação do Comitê de Ética para a realização de pesquisa foi iniciado o processo de validação do questionário. Em seguida, os objetivos da pesquisa foram explicitados a todos os 43 diretores das escolas municipais de educação infantil, em uma das reuniões mensais da equipe. Nessa reunião, foi informado a todos os diretores o compromisso das pesquisadoras em enviar, na entrega do questionário preenchido, um CD contendo artigos pertinentes sobre inclusão de crianças com problemas de comportamento, bem como uma apresentação em aplicativo Power Point (Microsoft Office®) sobre dicas para incluir crianças com comportamentos-problema. Após essa reunião, foram entregues à Coordenadora da Educação
Infantil da cidade, 43 envelopes que continham em seu interior uma carta de apresentação explicando os objetivos da pesquisa e a data de entrega do material para a Coordenadora da Educação Infantil, uma cópia do questionário e o Termo de Consentimento Livre e Esclarecido - TCLE. O preenchimento do questionário foi realizado em lugares de conveniênica para o diretor, tais como sua sala de trabalho ou residência. Após o período determinado na entrega do material (duas semanas), as pesquisadoras recolheram junto a Coordenadora da Educação Infantil do Município todos os questionários preenchidos e, em troca, foram deixados os CDs para aqueles diretores que entregaram seus questionários. Ao fim da análise de dados as pesquisadoras apresentaram os resultados à Secretaria de Educação do Município.

\section{Resultados}

Dos 43 questionários enviados, 40 foram devolvidos devidamente preenchidos, perfazendo um índice de $93 \%$ de retorno e participação dos diretores de escolas de educação infantil. Os dados iniciais dos questionário indicaram que o tempo que os diretores estavam na função variaram de 2 meses a 7 anos e 3 meses. O número de professores na escola variou entre 3 a 34. A quantidade de alunos variou de 47 a 490 alunos.

Antes de responder sobre a quantidade de alunos que apresentavam comportamentos-problema, os diretores foram solicitados a listar as características dos alunos que demonstravam comportamentos-problema na escola, segundo sua descrição pessoal. Essa pergunta era aberta e os diretores podiam nomear quantas características desejassem. Foram enumeradas 102 características por todos os diretores mas, para facilitar a análise dos dados essas características foram agrupadas entre si, segundo a convergência temática. Para identificação dos temas inseridos nas características foram utilizadas as definições semânticas segundo o dicionário Aurélio (Ferreira, 1988), as definições técnicas (Del Prette \& Del Prette, 1999; Del Prette \& Del Prette, 2001; Hallahan \& Kauffmam, 2003; Worthington \& Gargiulo, 2003) e os princípios da análise de conteúdo demonstrados em Manzini (1990/1991). Portanto, as 102 características foram agrupadas em 20 categorias, sendo que 4 características não puderam ser classificadas em nenhuma outra categoria (Tabela 1).

Notou-se que características relacionadas a déficits em Habilidades Sociais (brincar sozinho, dificuldades de interação, não conversa com os professores, dificuldades em ouvir o outro, fala demais, não quer amigos); agressividade (agressividade física, agressividade verbal, auto-agressão); dificuldades em seguir/obedecer regras (desobediência, indisciplina, não obedece quando chamado); dificuldades de concentração (distração, falta de concentração); apatia (falta de interesse, olhar "parado", passividade); comportamentos opositivos (birra, cuspir, faz coisas que incomodam, grita, mente, destroi coisas dos outros, tumultuam de próposito); hiperatividade (agitação, atividade motora intensa) e instabilidade emocional (afetividade instável, carência afetiva, insegurança) somam por $70 \%$ de todas as características listadas. 
Tabela 1. Categorias das características das crianças que apresentam comportamentos-problema apontados pelos diretores.

\begin{tabular}{|c|c|c|c|}
\hline & Categorias & Freq. & $\%$ \\
\hline 1 & Déficits em Habilidades Sociais & 39 & 14,8 \\
\hline 2 & Agressividade & 39 & 14,8 \\
\hline 3 & Dificuldades em seguir/obedecer regras & 21 & 8,0 \\
\hline 4 & Dificuldade de concentração & 20 & 7,6 \\
\hline 5 & Apatia & 19 & 7,2 \\
\hline 6 & Comportamentos opositivos & 18 & 6,8 \\
\hline 7 & Hiperatividade & 15 & 5,7 \\
\hline 8 & Instabilidade emocional & 15 & 5,7 \\
\hline 9 & Falta de atenção & 14 & 5,3 \\
\hline 10 & Ambiente com presença de fatores de risco & 11 & 4,2 \\
\hline 11 & Deficiência/ problemas no desenvolvimento & 11 & 4,2 \\
\hline 12 & Tristeza & 6 & 2,3 \\
\hline 13 & Irritabilidade & 6 & 2,3 \\
\hline 14 & Desafiador & 5 & 1,9 \\
\hline 15 & Ansiedade & 5 & 1,9 \\
\hline 16 & Dificuldades de aprendizagem & 4 & 1,5 \\
\hline 17 & Problemas de sexualidade & 4 & 1,5 \\
\hline 18 & Impulsividade & 3 & 1,1 \\
\hline 19 & Baixa autoestima & 2 & 0,8 \\
\hline 20 & Interesses específicos & 2 & 0,8 \\
\hline \multirow[t]{2}{*}{21} & Sem categorização (desorganização, dependência, grande autonomia, alegria) & 4 & 1,6 \\
\hline & TOTAL & 263 & 100 \\
\hline
\end{tabular}

Em relação à prevalência de crianças com comportamentos-problema, a maior parte dos diretores $(77,5 \%)$ afirmou que em suas escolas haviam crianças que apresentavam comportamentos-problema. Segundo a avaliação dos diretores das escolas, a frequência de alunos que apresentavam comportamentos-problema variou de uma criança a 203 crianças.

A Tabela 2 mostra as pessoas com quem os diretores costumam se reunir para conversar sobre os alunos que apresentam comportamentos-problema: entre estas, encontram-se com maior freqüência os pais/responsáveis $(17,5 \%)$, professores da escola $(13,1 \%)$, merendeiros(as) $(9,5 \%)$, professor(a) do aluno $(9,5 \%)$, equipe da Secretaria de Educação $(8 \%)$ e outros funcionários $(8 \%)$.

Nenhum diretor apontou a existência formal de um grupo de apoio composto por pessoas que estariam direta ou indiretamente envolvidas com a criança (por exemplo: alunos, professores, pais, coordenadores, psicólogo escolar) que por meio de decisões conjuntas teriam o objetivo de prover apoio aos alunos com comportamentos-problema.

Os dados referentes às estratégias utilizadas pelos diretores para coletar dados sobre onde, quando e com quem ocorriam os comportamentos-problema do aluno estão dispostos na Tabela 3.
Observou-se que perfazendo mais de $50 \%$ das estratégias utilizadas pelos diretores para coletar dados sobre onde, quando e com quem ocorriam os comportamentos-problema do aluno estão: conversar com a criança, observar a criança, conversar com outras crianças e conversar com a merendeira.

Em relação às estratégias educativas utilizadas pelos diretores para lidar com os comportamentos-problema dos alunos, observou-se (Tabela 4) que as estratégias de maior frequência foram: conversar com a criança $(13,3 \%)$, conversar com pais ou responsáveis $(13,3 \%)$, buscar ajuda na Secretaria de Educação (11,5\%), conversar com os professores $(7,1 \%)$ e conversar com o professor do aluno $(6,2 \%)$.

Por fim, a Tabela 5 mostra quais ações utilizadas pelos diretores para avaliar os resultados de suas estratégias educativas com os alunos com comportamentos-problema. As duas ações mais utilizadas para a avaliação das intervenções foram: observação da criança $(27,6 \%)$ e a mudança de comportamento da criança $(17,2 \%)$. Em seguida, observou-se que o relato de pais, funcionários, professores foram consideradas como as ações mais utilizadas.

Alguns dados foram excluídos da análise visto que 6,9\% dos diretores ao invés de descreverem as ações que utilizavam para avaliar as estratégias educativas, esses citaram alguns casos de alunos que melhoraram os problemas de comportamento ou descreveram a importância de se avaliar as intervenções. 
Tabela 2. Pessoas com as quais os diretores se reúnem com maior freqüência.

\begin{tabular}{|c|c|c|c|c|c|c|c|c|}
\hline & Pessoas envolvidas & Raramente & $\begin{array}{c}\text { Poucas } \\
\text { Vezes }\end{array}$ & $\begin{array}{c}\text { Algumas } \\
\text { vezes }\end{array}$ & $\begin{array}{l}\text { Várias } \\
\text { vezes }\end{array}$ & $\begin{array}{c}\text { Muitas } \\
\text { vezes }\end{array}$ & Total & $\%$ \\
\hline 1 & Pais/responsáveis & & 3 & 4 & 14 & 3 & 24 & 17,5 \\
\hline 2 & Professores & & & 2 & 1 & 15 & 18 & 13,1 \\
\hline 3 & Merendeira(o) & & 1 & 5 & 5 & 2 & 13 & 9,5 \\
\hline 4 & Professora(o) do aluno & & & 1 & 6 & 6 & 13 & 9,5 \\
\hline 5 & Equipe Secretaria de Educação & 1 & & 6 & 3 & 1 & 11 & 8,0 \\
\hline 6 & Funcionários & & & 4 & 6 & 1 & 11 & 8,0 \\
\hline \multirow[t]{2}{*}{7} & Aluno & & 1 & 1 & 2 & 2 & 6 & 4,4 \\
\hline & $\begin{array}{l}\text { Professora(o) de Educação } \\
\text { Especial }\end{array}$ & & & 1 & 2 & 2 & 5 & 3,6 \\
\hline 9 & Familiares & & 1 & 1 & & 2 & 4 & 2,9 \\
\hline 10 & Faxineiras(os) & & 1 & & & 3 & 4 & 2,9 \\
\hline 11 & Profissionais & & 1 & 2 & 1 & & 4 & 2,9 \\
\hline 12 & Psicóloga & & & 2 & 1 & 1 & 4 & 2,9 \\
\hline 13 & Colegas do aluno & & & & 3 & & 3 & 2,2 \\
\hline 14 & Mãe & & & & 2 & & 2 & 1,5 \\
\hline 15 & Professores Criando Asas & & & & & 2 & 2 & 1,5 \\
\hline 16 & Conselho de escola & & & 1 & & & 1 & 0,7 \\
\hline 17 & Cooperados & & & & 1 & & 1 & 0,7 \\
\hline 18 & Dentista & & & 1 & & & 1 & 0,7 \\
\hline 19 & Educadores & & & & & 1 & 1 & 0,7 \\
\hline 20 & Filhos da diretora & & & & & 1 & 1 & 0,7 \\
\hline 21 & Marido da diretora & & & & & 1 & 1 & 0,7 \\
\hline 22 & Médico(a) & & & & 1 & & 1 & 0,7 \\
\hline 23 & Outros diretores & & & 1 & & & 1 & 0,7 \\
\hline 24 & Pai & & 1 & & & & 1 & 0,7 \\
\hline 25 & Parceiros da comunidade & & & & 1 & & 1 & 0,7 \\
\hline 26 & Porteiro & & & 1 & & & 1 & $\mathbf{0 , 7}$ \\
\hline 27 & Prof. Educação Física & & & & & 1 & 1 & 0,7 \\
\hline 28 & Psicopedagoga(o) & & & 1 & & & 1 & $\mathbf{0 , 7}$ \\
\hline & Total & 1 & 9 & 34 & 49 & 44 & 137 & 100 \\
\hline
\end{tabular}

Legenda: Raramente- Passa-se anos sem conversar; Poucas vezes- De a cada 4 meses a um ano; Algumas vezes- De uma vez por mês até a cada 3 meses; Várias vezes- De uma vez por semana até a cada 15 dias; Muitas vezes- De todos os dias até várias vezes durante a semana

\section{Discussão}

O estudo possibilitou uma avaliação formal do conhecimento da escola sobre as estratégias educacionais utilizadas e, adicionalmente, a geração de uma linha de base para elaboração e comparação de outras pesquisas com amostras e temáticas semelhantes.

Em geral, os resultados apontaram que as estratégias educativas descritas pelos diretores das escolas de educação infantil foram realizadas informal e assistematicamente. Tal dado, ainda que obtido a partir de uma amostra pequena e regional, parece sustentar a hipótese do estudo de que a forma como as estratégias educativas para comportamentos-problema de crianças são elaboradas, aplicadas e avaliadas são realizadas sem rigor metodógico para coletar dados, formular hipóteses, gerar intervenções e avaliar essas intervenções.

Visando ampliação dos resultados obtidos nesse estudo, sugere-se que outras pesquisas sejam realizadas com outras amostras, tais como, diretores de rede privada, professores de rede pública e privada e profissionais de outras regiões.

A escolha pelo uso do questionário deu-se em função de suas características positivas expressas por baixo custo em comparação com entrevistas e possibilidade de aplicação em grupo (Cozby, 2003). A pesquisa apresentou uma alta taxa de retorno dos questionários $(93 \%)$ o que indica menores possibilidades de vieses na amostra e maiores possibilidades de generalização dos resultados para a população de interesse (Cozby, 2003). Sugere-se que alta taxa de retorno esteja 
Tabela 3. Estratégias utilizadas pelos diretores para identificar onde, quando e com quem ocorriam os comportamentos-problema do aluno.

\begin{tabular}{|c|c|c|c|c|c|}
\hline & ONDE & QUANDO & QUEM & TOTAL & $\%$ \\
\hline Conversa com a criança & 16 & 6 & 8 & 30 & 17,9 \\
\hline Observa a criança & 1 & 15 & 13 & 29 & 17,3 \\
\hline Conversa com as outras crianças & 6 & 5 & 6 & 17 & 10,1 \\
\hline Conversa com a merendeira & 13 & 1 & & 14 & 8,3 \\
\hline Conversa com os funcionários da escola & 4 & 4 & 6 & 14 & 8,3 \\
\hline Conversa com o professor do aluno & 6 & 5 & 2 & 13 & 7,7 \\
\hline Conversa com os familiares da criança & 5 & 3 & 2 & 10 & 6,0 \\
\hline Conversa com as pessoas com quem a criança convive & 3 & 2 & 5 & 10 & 6,0 \\
\hline Conversa com os pais/responsáveis & 3 & 2 & 2 & 7 & 4,2 \\
\hline Conversa com outros professores & & 2 & 4 & 6 & 3,6 \\
\hline Solicita observação do professor & 1 & 2 & & 3 & 1,8 \\
\hline Solicita observação dos funcionários & 1 & 1 & 1 & 3 & 1,8 \\
\hline Conversa com quem reclamou da criança & & & 2 & 2 & 1,2 \\
\hline Escuta & & & 2 & 2 & 1,2 \\
\hline Solicita observação dos pais & 1 & 1 & & 2 & 1,2 \\
\hline Solicita observação dos professores & & & 2 & 2 & 1,2 \\
\hline Acompanha os diários de trabalho pedagógico & & 1 & & 1 & 0,6 \\
\hline Mudança de estratégias & & 1 & & 1 & 0,6 \\
\hline Solicta observação das pessoas com quem a criança convive & & 1 & & 1 & 0,6 \\
\hline Verifica caderno de registros dos professores & & 1 & & 1 & 0,6 \\
\hline TOTAL & 60 & 53 & 55 & 168 & 100,0 \\
\hline
\end{tabular}

associada aos métodos utilizados pelas pesquisadoras para maximização da entrega dos questionários, tais como: (1) carta de apresentação das pesquisadoras com explicações básicas sobre a pesquisa e explicações sobre a importância e significância da participação; (2) possibilidade de receber um incentivo (CD com artigos científicos e apresentação sobre comportamentos-problema em aplicativo Power Point- Microsoft () ) ao devolver o questionário preenchido. Por outro lado, pontua-se o fato de que os dados advindos do questionário são auto-descrições dependentes da capacidade individual do respondente em ler e compreender as questões, gerando vieses nas respostas (Cozby, 2003).

Ainda com relação ao questionário utilizado nessa pesquisa, postula-se que o mesmo ainda necessite de maiores reformulações e mais estudos sobre sua validade. Apesar de as pesquisadoras procurarem o parecer de juízes para avaliar o instrumento seguida de pequena aplicação piloto, os resultados indicaram que alguns diretores tiveram dificuldades em preencher o questionário, indicando a necessidade de aprimoramentos no instrumento. Adicionalmente, o questionário utilizado na pesquisa buscou informações básicas a respeito do processo de elaboração, aplicação e avaliação de estratégias educacionais, sugere-se que para obtenção de informações mais detalhadas sejam utilizadas outras medidas de coleta de dados que permitam maior detalhamento das informações obtidas, como por exemplo, o uso de entrevistas, observações ou metodologias combinadas.

Especificamente em relação aos dados advindos das perguntas do questionário, observou-se que as características das crianças com comportamentos-problema apontados pelos diretores se assemelham às apontadas pela literatura (Bandeira \& cols., 2006; Bolsoni-Silva \& cols., 2006; Ferreira \& Marturano, 2002; Hallahan \& Kauffmam, 2003; Marinho, 2003; Worthington \& Gargiulo, 2003). Hipotetiza-se, por um lado, que os diretores possuem o conhecimento das características dos alunos que apresentam comportamentos-problema; ou que, os diretores apresentam um vocabulário comum para caracterizar esses alunos, possivelmente fruto das capacitações profissionais que os diretores participam e dos materiais sobre o assunto fornecido pelo Ministério da Educação.

Apesar da identificação das características dos alunos com problemas de comportamento favorecer a formação de rótulos que, muitas vezes, reduzem crianças a estereótipos e quadros sintomáticos (Campos, 1997), considera-se, ainda, sua importância em nosso cotidiano, por causa da sua funcionalidade lingüística que facilita o entendimento e a ação frente a certas condições que exigem atendimento educacional especializado (Campos, 1997; Denari, 2006). De qualquer forma, Campos (1997) enfatiza a necessidade de clareza de significados das definições e características para que assim seu uso possa ser mais cauteloso e crítico.

Segundo o enfoque do Apoio Comportamental PositivoPBS, os dados advindos sobre com que pessoas os diretores costumam se reunir para conversar sobre os alunos que apresentam comportamentos-problema forneceria dados sobre a existência do grupo de apoio que deveria ser composto por pessoas que estejam envolvidas direta ou indire- 
Tabela 4. Estratégias utilizadas pelos diretores para lidar com os comportamentos-problema do aluno

\begin{tabular}{|c|c|c|c|}
\hline & Estratégias & Freq. & $\%$ \\
\hline 1 & Conversa com a criança & 15 & 13,3 \\
\hline 2 & Conversa com pais ou responsáveis & 15 & 13,3 \\
\hline 3 & Busca ajuda da Secretaria de Educação & 13 & 11,5 \\
\hline 4 & Conversa com professores & 8 & 7,1 \\
\hline 5 & Conversa com o professor & 7 & 6,2 \\
\hline 6 & Conversa com todos envolvidos na situação & 6 & 5,3 \\
\hline 7 & Conversa com as crianças & 5 & 4,4 \\
\hline 8 & Conversa com profissionais especializados & 5 & 4,4 \\
\hline 9 & Orienta familiares & 4 & 3,5 \\
\hline 10 & Conversa com família & 3 & 2,7 \\
\hline 11 & Orienta professor & 3 & 2,7 \\
\hline 12 & Conversa com os funcionários & 2 & 1,8 \\
\hline 13 & Conversa com prof. de Educação Especial & 2 & 1,8 \\
\hline 14 & Encaminha caso para a Secretaria de Educação & 2 & 1,8 \\
\hline 15 & Pesquisa sobre o assunto & 2 & 1,8 \\
\hline 16 & Reunião de pais & 2 & 1,8 \\
\hline 17 & Palestras para os pais & 2 & 1,8 \\
\hline 18 & Orienta funcionários da escola & 2 & 1,8 \\
\hline 19 & Antecipa a situação & 1 & 0,9 \\
\hline 20 & Cria ambiente mais agradável e estimulador & 1 & 0,9 \\
\hline 21 & Estabelecimento de rotinas & 1 & 0,9 \\
\hline 22 & Ter atitudes positivas & 1 & 0,9 \\
\hline 23 & Evita bate boca com a criança & 1 & 0,9 \\
\hline 24 & Mudança de estratégia pedagógica & 1 & 0,9 \\
\hline 25 & Identifica o problema & 1 & 0,9 \\
\hline 26 & Atividade lúdicas adaptadas às necessidades dos alunos & 1 & 0,9 \\
\hline 27 & $\begin{array}{l}\text { Troca de informações com família, educadores, equipe de apoio, comunidade e } \\
\text { especialistas }\end{array}$ & 1 & 0,9 \\
\hline 28 & Encaminhamento para diagnóstico com profissionais de saúde & 1 & 0,9 \\
\hline 29 & Cobra atitutes enérgicas dos professores & 1 & 0,9 \\
\hline 30 & Fica próximo do funcionário que está cuidando da criança para dar orientação & 1 & 0,9 \\
\hline 31 & Sensibilização & 1 & 0,9 \\
\hline 32 & Reunião entre pais, diretor e professor & 1 & 0,9 \\
\hline \multirow[t]{2}{*}{33} & Reunião entre pais, diretor e SMEC & 1 & 0,9 \\
\hline & TOTAL & 113 & 100 \\
\hline
\end{tabular}

tamente com a criança (por exemplo: alunos, professores, pais, coordenadores, psicólogo escolar etc.), com o intuito de resolver problemas e prover apoio a esses alunos com comportamentos-problemas por meio de uma comunicação aberta, honesta e respeitosa, buscando os mesmos objetivos, dividindo responsabilidades e resolvendo conflitos por meio de consenso (Heineman \& cols., 2005). A partir dos dados obtidos com o questionário, pontua-se que, apesar do contato dos diretores com pessoas inseridas em diversos ambientes relacionados direta ou indiretamente à criança, esse contato seria realizado de forma emergencial e circunstancial, ou seja, não havendo formação de grupos ou encontros sistemáticos visando resolver os comportamentos-problema enfrentados pela escola de forma consensual e preventiva.

Segundo o enfoque PBS, os dados referentes a onde, quando e com quem os comportamentos-problema do aluno ocorrem são considerados informações essenciais para a formulação de hipóteses que direcionarão a intervenção (Conroy \& Sticher, 2003; Ervin \& cols., 2001; Reid \& Nelson, 2002; Scott \& Eber, 2003). Essas informações devem ser coletadas a partir de várias fontes, tais como registros, entrevistas, observações, favorecendo a triangulação dos dados (Adorno \& Castro, 1994). No presente estudo, os dados referentes às estratégias utilizadas pelos diretores para 
Tabela 5. Estratégias utilizadas pelos diretores para avaliar os resultados de suas intervenções com os comportamentosproblema do aluno

\begin{tabular}{lcc}
\hline Estratégias & Freq. & $\mathbf{\%}$ \\
\hline Observação do aluno & 16 & 27,6 \\
Mudança de comportamento da criança & 10 & 17,2 \\
Conversa com pais/responsáveis & 4 & 6,9 \\
Conversa com os funcionários & 3 & 5,2 \\
Conversa com professor do aluno & 3 & 5,2 \\
Conversa com professores & 3 & 5,2 \\
Analisa-se o desenvolvimento do aluno & 3 & 5,2 \\
Mudança no comportamento de todos envolvidos & 2 & 3,4 \\
Relato dos profissionais de saúde que acompanham o aluno & 2 & 3,4 \\
Acompanha o dia a dia & 1 & 1,7 \\
Conversa com a criança & 1 & 1,7 \\
Conversa com todos envolvidos & 1 & 1,7 \\
Verifica-se se houve diminuição da agressividade & 1 & 1,7 \\
Mudança na socialização com outras crianças & 1 & 1,7 \\
Pais participam da vida escolar & 1 & 1,7 \\
Refletindo sobre as atitudes tomadas & 1 & 1,7 \\
Relato do professor educação especial & 1 & 1,7 \\
Não respondeu adequadamente & 4 & 6,9 \\
\hline TOTAL & 58 & 100 \\
\hline
\end{tabular}

coletar dados sobre onde, quando e com quem ocorriam os comportamentos-problema do aluno demonstraram que as estratégias de coleta de dados de uso mais freqüente são relatos, seguidas por observações e análise documental de registros. Nenhum diretor apontou o uso de entrevistas, questionários, inventários ou avaliações de profissionais.

Em geral as estratégias, descritas pelos diretores, utilizadas para coletar os dados sobre onde, quando e com quem ocorriam os comportamentos-problema do aluno demonstraram características de informalidade e não sistematização da investigação que acabam por interferir no processo de formulação de hipóteses, que deveriam ser testadas (pela manipulação de variáveis) com o intuito de identificar quais fatores estariam relacionados ao comportamento problemático para, enfim, serem administradas as intervenções e avaliações (Reid \& Nelson, 2002). A imprecisão da formulação das hipóteses influenciaria nos delineamentos de ações/intervenções para ajudar os alunos com comportamentos-problema.

$\mathrm{O}$ enfoque PBS pontua que para uma intervenção ser realizada de forma eficiente, ela deveria utilizar-se de multicomponentes e incluir estratégias que objetivassem prevenir problemas pela modificação das condições do ambiente, ensinar repertórios novos para substituir os comportamentos inadequados e prover conseqüências positivas para os comportamentos adequados (Heineman \& cols., 2005; Reid \& Nelson, 2002). Os dados sobre as estratégias educativas utilizadas pelos diretores para lidar com os comportamentos-problema dos alunos indicaram uma baixa freqüência de estratégias que objetivam a modificação do ambiente e o uso de conseqüências positivas (criar ambiente mais agradável e estimulador, estabelecer rotinas, atitudes positivas, mudança de estratégia pedagógica, por exemplo). Os diretores não descreveram nenhuma estratégia educativa que procurasse ensinar repertórios novos para substituir os comportamentos inadequados.

Um fato interessante foi o uso da técnica "cobrar atitudes mais enérgicas dos professores". Essa estratégia pode estar relacionada ao uso de punições como forma de disciplina e correção de comportamentos inadequados por parte da criança. Tal estratégia além de ineficaz está relacionada ao aumento de comportamentos-problema (Bandeira \& cols., 2006; Ferreira \& Marturano, 2002; Ormeño \& Williams, 2006; Picado \& De Rose, 2009;) e a problemas de aprendizagem e socialização (Jacob, 2001; Marturano, 2004; Marturano \& cols., 1997).

Segundo o enfoque PBS a forma como as estratégias educativas devem ser avaliadas pode variar conforme as circunstâncias, mas, em geral, incluem medidas de freqüência dos comportamentos-alvo, uso de escalas ou checklists, observações, medidas de satisfação e medidas advindas de outros sistemas relacionados à criança (Heineman \& cols., 2005). Os dados advindos do questionário utilizado no presente estudo apontaram que os diretores não mencionaram o uso de escalas, checklists ou medidas de satisfação para verificação de mudanças nos comportamentos-alvo da intervenção e, também, para identificar alterações consideradas positivas em outros ambientes que a criança se relaciona. Em geral, as técnicas para avaliação das estratégias educativas basearam-se em relatos verbais das pessoas envolvidas direta ou indiretamente com a criança. Pontua-se que os relatos verbais são subjetivos e de difícil operacionalização e que provavelmente as avaliações baseadas nessa metodologia 
tenderão a ser de pouca validade ou fidedignidade. Verifica-se a necessidade de maior sistematização das avaliações e uniformização das metodologias para garantir que os dados avaliados possam demonstrar a validade das estratégias educativas utilizadas.

Comparando-se a metodologia descrita pelos diretores sobre o processo de elaboração, implementação e avaliação das estratégias educativas para os comportamentos-problema dos alunos com a metodologia proposta pelo enfoque PBS, observou-se que a metodologia descrita pelos diretores de educação infantil é caracterizada pela informalidade, ausência de sistematização, além do fato de serem realizadas de forma emergencial e circunstancial.

Sobre os possíveis fatores que contribuem para a informalidade e assistematização das estratégais educativas utilizadas nas escolas de educação infantil, Campos e cols. (2006) discutem que essa situação é amplamente complexa e que uma primeira análise deve se basear na maneira pela qual foi construída a educação infantil no Brasil, em que leis foram formuladas exigindo-se, em seguida, que a realidade complexa da educação brasileira se modificasse para cumprimento dessas exigências legais. Tal situação acabou por criar um descompasso entre as concepções defendidas pelos documentos legais, o discurso das equipes de supervisão, o planejamento das unidades e as práticas observadas no cotidiano escolar. Ainda segundo os autores a educação infantil no Brasil pode ser caracterizada pela carência de material pedagógico, carência de estrutura física adequada, não qualificação dos profissionais e baixa remuneração dos profissionais (Campos \& cols., 2006).

Para Rios e Denari (2008) os fatores que tem contribuído para a informalidade e não sistematização da elaboração, implementação e avaliação das estratégais educativas estariam relacionados com: (1) a formação incial e continuada dos educadores que não tem fornecido subsídios teóricos e práticos para a atuação junto aos comportamentos-problema dos alunos; (2) ausência de repertório dos educadores para desenvolver outras alternativas de estratégias educativas que não sejam punitivas e, (3) dificuldades da escola em se comunicar com a família e outras pessoas envolvidas com a criança a fim de pensarem juntos a respeito do manejo dos comportamentos-problema da criança.

Dessa maneira, o presente estudo aponta a necessidade de aprimoramento na formação inicial e continuada de educadores a fim de que os mesmos possam desenvolver competências necessárias para a análise e intervenção frente aos comportamentos-problemas dos alunos. Acredita-se, também, que o desenvolvimento de pesquisas na área de comportamentos-problema e estratégias educativas seja importante tanto para a aquisição e refinamento de conhecimentos específicos, tanto quanto para gerar critérios avaliativos que permitam o avanço teórico-prático nessa temática. Nesse sentido, o presente estudo oferece uma linha de base inicial para que outras pesquisas possam se utilizar dos resultados e discussões aqui apresentados com intuito de desenvolver outras investigações.

Foi observado no presente estudo que o processo de elaboração, implementação e avaliação das estratégias educativas, descritos pelos diretores de escola de educação infantil, para o manejo de comportamentos-problema em alunos foram realizadas informalmente e assistematicamente, expressos pela carência de rigor metodológico para para coletar dados, formular hipóteses, gerar intervenções e avaliar essas intervenções.

Aponta-se a necessidade de mais pesquisas sobre o fenômeno da inclusão de crianças com comportamentos-problemas visando aumentar o conhecimento sobre a temática e aprimoramento das estratégias educativas. E, principalmente, instaura-se, urgentemente, o desafio de mudar a formação inicial e continuada dos educadores visando o desenvolvimento de um processo crítico-reflexivo e que seja contínuo. Além disso, permitir aos educadores, trabalharem de forma preventiva, envolvendo vários profissionais e indivíduos dos ambientes relacionados direta ou indiretamente à criança. Este passo é necessário para buscar estratégias focadas na realidade; e, que estas sirvam de base para a elaboração de hipóteses testadas e transformadas em práticas realmente eficazes. Daí, certamente, resultarão conhecimentos relevantes para intervenções cada vez mais elaboradas e delineadas com a realidade que as precede e as mantém.

\section{Referências}

Adorno, R. C. F., \& Castro, A. L. (1994). O exercício da sensibilidade: Pesquisa qualitativa e a saúde como qualidade. Saúde e Sociedade, 3(2), 172-85.

Bandeira, M., Rocha, S. S., Souza, T. M. P., Del Prette, Z. A. P., \& Del Prette, A. (2006). Comportamentos problemáticos em estudantes do ensino fundamental: Características da ocorrência e relação com habilidades sociais e dificuldades de aprendizagem. Estudos de Psicologia, 11(2), 199-208.

Baraldi, D. M., \& Silvares, E. F. M. (2003). Treino de habilidades sociais em grupo com crianças agressivas, associado à orientação dos pais: Análise empírica de uma proposta de atendimento. Em A. Del Prette \& Z. A. P. Del Prette (Eds.), Habilidades sociais, desenvolvimento e aprendizagem (pp. 235-258). Campinas, SP: Alínea.

Bolsoni-Silva, A. T., \& Marturano, E. M. (2002). Práticas educativas e problemas de comportamento: Uma análise à luz das habilidades sociais. Estudos de Psicologia, 7(2), 227-235.

Bolsoni-Silva, A. T., Marturano, E. M., Pereira, V. A., \& Manfrinato, J. W. S. (2006). Habilidades Sociais e problemas de comportamento de pré-escolares: Comparando avaliações de mães e de professoras. Psicologia: Reflexão e Crítica, 19(3), 460-469.

Campos, L. M. L. (1997). A rotulação de alunos como portadores de "distúrbios ou dificuldades de aprendizagem": Uma questão a ser refletida. Série Idéias, 28, 125-140.

Campos, M. M., Füllgraf, J., \& Wiggers, V.(2006). A qualidade da educação infantil brasileira: Alguns resultados de pesquisa. Cadernos de Pesquisa, 36(127), 87-128

Candau, V. M. F. (1996). Formação continuada de professores: Tendências atuais. Em A. M. M. R. Reali \& M. G. N. Mizukami (Eds.), Formação de professores: Tendências atuais (inserir os números das páginas - inicial e final - referentes a esse capítulo). São Carlos, SP: EDUFSCar. 
Carr, E. G., Dunlap, G., Horner, R. H., Koegel, R. L., Turnbull, A. P., Sailor, W., Anderson, J., Albin, R. W., Koegel, L. K., \& Fox, L. (2002). Positive behavior support: Evolution of an applied science. Journal of Positive Behavior Interventions, 4(1), 4-16.

Carr, E. G., Horner, R. H., Turnbull, A. P., Marquis, J., Magito-Mclaughlin, D., McAtee, M. L., Smith, C. E., Anderson-Ryan, K., Ruef, M. B., \& Doolabh, A. (1999). Positive behavior support for people with developmental disabilities: A research synthesis. Washington, DC: American Association on Mental Retardation.

Conroy, M. A., \& Stichter, J. P. (2003). The application of antecedents in the Functional Assessment Process: Existing research, issues, and recommendations. The Journal of Special Education, 37(1), 15-25.

Cozby, P. C. (2003). Métodos de pesquisa em ciências do comportamento. São Paulo: Editora Atlas.

Del Prette, A., \& Del Prette, Z. A. P. (2001). Psicologia das relações interpessoais: Vivências para o trabalho em grupo. Petrópolis, RJ: Vozes

Del Prette, Z. A. P., \& Del Prette, A. (1999). Psicologia das habilidades sociais: Terapia e educação. Petrópolis, RJ: Vozes.

Denari, F. (2006). Um (novo) olhar sobre a formação do professor de educação especial: Da segregação à inclusão. Em D. Rodrigues (Ed.), Inclusão e Educação: doze olhares sobre a educação inclusiva. São Paulo: Summus.

Ervin, R. A., Radford, P. M., Bertsch, K., Piper, A. L., Ehrhardt, K. E., \& Poling, A. (2001). A descriptive analysis and critique of the empirical literature on school-based functional assessment. School Psychology Review,30(2), 193-210.

Ferreira, A. B. H. (1988). Dicionário Aurélio básico da língua portuguesa. Rio de Janeiro: Nova Fronteira.

Ferreira, M. C. T., \& Marturano, E. M. (2002). Ambiente familiar e os problemas de comportamentos apresentados por crianças com baixo desempenho escolar. Psicologia: Reflexão e Crítica, 15(1), 35-44.

Gallo, A. E., \& Williams, L. C. A. (2006). Adolescentes em conflito com a lei: Uma revisão dos fatores de risco para a conduta infracional. Psicologia: Teoria e Prática, 7(1), 81-95.

Gomide, P. I. C. (2003). Estilos parentais e comportamento anti-social. Em A. Del Prette \& Z. A. D. Del Prette (Eds.). Habilidades sociais, desenvolvimento e aprendizagem (pp. 21- 60). Campinas, SP: Alínea.

Hallahan, D. P., \& Kauffman, J. M. (2003). Exceptional learners: Introduction to special education. Boston, MA: Allyn and Bacon.

Heineman, M., Dunlap, G., \& Kincaid, D. (2005). Positive support strategies for students with behavioral disorders in general education settings. Psychology in the schools, 42(8), 779-794.

Jacob, A. (2001). O desempenho escolar e suas relações com autoconceito e auto-eficácia. Tese de Doutorado, Universidade de São Paulo, Ribeirão Preto, São Paulo.

Manzini, E. J. (1990/1991). A entrevista na pesquisa social. Didática, 26/27, 149-158.

Marinho, M. L. (2003). Comportamento anti-social infantil: Questões teóricas e de pesquisa. Em A. Del Prette\& Z. A. D. Del Prette (Eds.). Habilidades sociais: desenvolvimento e aprendizagem (pp. 21-60). Campinas, SP: Alínea.
Marturano, E. M. (2004). Fatores de risco e proteção e proteção no desenvolvimento sócio-emocional de crianças com dificuldade de aprendizagem. Em E. G Mendes, M. A. Almeida \& L. C. A. Williams, (Eds.), Temas em educação especial (pp. 159-165). São Carlos, SP: EDUFSCar.

Marturano, E. M., Linhares, M. B. M.; Loureiro, S. R.; \& Machado, V. L. (1997). Crianças referidas para atendimento psicológico em virtude de baixo rendimento escolar: Comparação com alunos não referidos. Revista Interamericana de Psicologia, 31(2), 223-241.

Medeiros, P. C., Loureiro, S. R., Linhares, M. B., \& Marturano, E. M. (2000). A auto-eficácia e os aspectos comportamentais de crianças com dificuldade de aprendizagem. Psicologia: Reflexão e Crítica, 13(3), 327-336.

MEC/INEP (2005). Dados do Censo Escolar de 2005. Retirado de http://portal.mec.gov.br/seesp

Ormeño, G. R., \& Williams, L. C. A. (2006). Intervenção precoce com crianças agressivas: Suporte à família e à escola. Em H. H. Guilhardi \& N. C. Aguirre (Eds.), Sobre comportamento e cognição: Expondo a variabilidade. (V.17). (pp 168-182). Santo André, SP: ESETec.

Patterson, G. R., Reid, J. B. \& Dishion, T. J. (1992). Antisocial boys: A social interactional approach. Eugene, OR: Castalia.

Picado, J. R., \& De Rose, T. M. S. (2009). Acompanhamento de préescolares agressivos: adaptação na escola e relação professoraluno. Psicologia: Ciencia e Profissão, 29(1), 132 -145.

Pinheiro, M. I. S., Haase, V. G., Del Prette, A., Amarantea, C. L. D., \& Del Prette, Z. A. P. (2006). Treinamento de habilidades sociais educativas para pais de crianças com problemas de comportamento. Psicologia: Reflexão e Crítica, 19(3), 407414.

Reid, R., \& Nelson, J. R. (2002). The utility, acceptability, and practicality of Functional Behavioral Assessment for students with high-incidence of problem behaviors. Remedial and Special Education, 23(1), 15-23.

Reid, M. J., Webster-Stratton, C., \& Beauchaine, T. P. (2001). Parent training in head start: A comparison of program response among African American, Asian American, Caucasian, and Hispanic Mothers. Prevention Science, 2(4), 209-227.

Rios, K. S. A., \& Denari, F. E. (2008). Reflexões a respeito da inclusão de crianças com problemas de comportamento. Em F. E. Denari (Ed.), Igualdade, diversidade e educação (mais) inclusiva. (pp 111-129). São Carlos, SP: Pedro e João Editores.

Rios, K. S. A., \& Williams, L. C. A. (2008). Intervenção com famílias como estratégia de prevenção de problemas de comportamento em crianças: Uma revisão. Psicologia em Estudo, 13(4), 799-806.

Rosales-Ruiz, J., \& Baer, D. M. (1997). Behavioral cusps: A developmental and pragmatic concept for behavior analysis. Journal of Applied Behavior Analysis, 30(3), 533-544.

Salvo, C. G., Silvares, E. F. M., \& Toni, P. M. (2005). Práticas educativas como forma de predição de problemas de comportamento e competência social. Estudos de Psicologia, 22(2), 187-195.

Safran, S. P., \& Oswald, K. (2003). Positive Behavior Supports: Can schools reshape disciplinary practices? Exceptional Children, 69(3), 361-373. 
Santos, G. E., \& Williams, L C. A. (2006). Proposta de atendimento a pais agressores: Uma proposta em educação especial. Em M. P. R. Costa \& F. E. Denari (Eds.), Educação especial: Diversidades de olhares (pp 205- 216). São Carlos, SP: Pedro \& João Editores.

Scott, T. M., \& Eber, L. (2003). Functional assessment and wraparound as systemic school processes: Primary, secondary, and tertiary systems examples. Journal of Positive Behavior Interventions, 5(3), 131-143.

Serra-Pinheiro, M. A., Guimarães, M. M., \& Serrano, M. E. (2005). The effectiveness of parent management training in a Brazilian sample of patients with oppositional-defiant disorder. Revista de Psiquiatria Clínica, 32(2), 68-72.

Skinner, F. B. (1998). Ciência e comportamento humano (10 ${ }^{\mathrm{a}} \mathrm{Ed}$. Tradução: J.C. Todorov). São Paulo: Martins Fontes. (Obra originalmente publicada em 1953).

Sugai, G., Horner, R. H., Dunlap, G., Heineman, M., Lewis, T. J., Nelson, C. M., Scott, T., Liaupsin, C., Sailor, W., Turnbull, A. P., Rutherford III, H., Wickman, D., Ruef, M., \& Wilcox, Brenan (2000). Applying Positive Behavior Support and Functional Behavioral Assessment in schools. Journal of Positive Behavior Interventions, 2(3), 131-143.
Weber, L. N. D., Viezzer, A. P., \& Brandenburg, O. J. (2004). O uso de palmadas e surras como prática educativa. Estudos de Psicologia, 9(2), 227-237.

Webster-Stratton, C., Reid, M. J., \& Hammond, M. (2004). Treating children with early-onset conduct problems: Intervention outcomes for parent, child, and teacher training. Journal of Clinical Child and Adolescent Psychology, 33(1), 105-124.

Worthington, L. A., \& Gargiulo, R. M. (2003). Persons with emotional or behavioral disorders. Em R. M. Gargiulo (Ed.), Special education in contemporary society: An introduction to exceptionality. Belmont, CA, Wadsworth.

Recebido em 20.05.2009

Primeira decisão editorial em 11.01.2010

Versão final em 19.02.2010

Aceito em 07.01.2011

\section{CONVENCIÓN ANUAL DE LA ASOCIACIÓN INTERNACIONAL DE LECTURA "EL PODER DE LA ALFABETIZACIÓN"}

Local: 08 de Maio - 11 Maio 2011

Período: Orlando, Florida, US 